\title{
High rate of diabetes in the Asia-Pacific Island: Possible role of rapid urbanization - A hospital based study
}

\author{
Rhoda K. Ila ${ }^{l}$, Venkat N. Vangaveti ${ }^{2}$, Usman H. Malabu ${ }^{3}$
}

\begin{abstract}
${ }^{1}$ Medical Officer; Kimbe General Hospital, Papua New Guinea and ${ }^{2}$ Senior Research Officer; ${ }^{3}$ Associate Professor; Translational Research in Endocrinology and Diabetes [TREAD], James Cook University \& Department of Diabetes and Endocrinology, The Townsville Hospital; 100 Angus Smith Drive Douglas QLD 4814 Australia.
\end{abstract}

\section{Abstract}

Asia-Pacific countries are experiencing lifestyle-related non-communicable disease crises. Kimbe, one of Papua New Guinea's provincial capitals is noted as the fastest growing city in the South Pacific subcontinent yet its impact on diabetes mellitus (DM) is not known. To determine pattern of newly diagnosed DM, we conducted a retrospective review of Kimbe General Hospital medical admissions from January 2009 to December 2012. 125 patients were diagnosed with diabetes with male: female ratio of 1.1: 1. Overall, number of patients diagnosed with DM at the hospital increased rapidly from 16 in 2009 to 49 in 2012; $p<0.05$. Majority of the patients were of young population aged $<50$ years representing $72 \%$ of the cohort and predominantly of coastal province of origin. Almost $3 / 4^{\text {th }}$ of the study population was based in Kimbe town and its suburb with only 32 subjects $(25.6 \%)$ identified as rural residents; $\mathrm{p}<0.05$. This study suggests that subjects living in Asia-Pacific area of rapid urbanization are at higher risk of diabetes compared to residents of rural areas. It highlights the need for adequate health planning and education as part of urbanization program in the DM-prone Asia-Pacific population. Further prospective studies are needed to verify our findings.

Keywords: Diabetes, Newly diagnosed, Urbanization, Papua New Guinea, Asia-Pacific.

\section{Introduction}

According to World Health Organisation (WHO) 2016 Report, the number of people living with diabetes has nearly quadrupled since 1980 to 422 million adults in 2014, with most (over 80\%) living in developing countries. ${ }^{1}$ Indeed, $80 \%$ of chronic diseases occur in lowand middle-income countries and it is estimated that 7.1 million people will die annually as a result of diabetes. ${ }^{2}$

Pacific Island countries are predicted to experience among the greatest increases in diabetes prevalence due in part to rapid urbanization, increased rural-urban migration and change in life style. ${ }^{3}$ In support of this, hospital statistics in the region have shown that diabetes and obesity amongst other non-communicable diseases have increased since 1980. For instance, a pilot survey conducted in Papua New Guinea (PNG) working population in 2008 showed that $10 \%$ had a high blood glucose levels with no symptoms of diabetes.

The WHO STEPwise approach to Surveillance (STEPs) national prevalence study in 2008-9 showed that $14.4 \%$ of PNG adults aged 15-64 years had a fasting blood glucose level of $\geq 6.1 \mathrm{mmol} / \mathrm{L}$. ${ }^{4}$ It is estimated that there are over 200,000 people in PNG suffering from diabetes and of these only 5,000 are known to health services. ${ }^{5}$ That means that more than $97 \%$ of people are undiagnosed.

Furthermore, studies in the national capital and its suburb showed an exponential rise of diabetes in urban and immigrant coastal areas ${ }^{6,7}$ but no study conducted in other metropolitan cities with similar profile in the country. With the recent industrial palm oil and mining boom in West New Britain province, Kimbe the state

\section{Practice Points}

- Asia-Pacific Island countries have witnessed the world's highest prevalence of diabetes in recent years.

- The exponential increase in rate of diabetes in the region is thought to be associated with rapid increase in urban population.

- In a hospital-based study of a typical fastgrowing Asia-Pacific town we have shown a soaring rate of diabetes within short period of time most of whom were of young working population aged $<50$ years.

- This study suggests that subjects living in AsiaPacific area of rapid urbanization are at higher risk of diabetes compared to residents of rural areas.

- It highlights the need for adequate health planning and education as part of urbanization program in the DM-prone Asia-Pacific population.

capital is recognised as the fastest growing city in west pacific region ${ }^{8,9}$ with high rate of rural-urban migration, yet to date no report on its effect on diabetes.

The aim of the study was to determine pattern of hospital admission of newly diagnosed diabetes in subjects who live in Kimbe urban compared to those who live in rural areas.

Correspondence: Associate Professor Usman H. Malabu, Townsville Clinical School, James Cook University School of Medicine and Dentistry, Townsville Hospital, 100 Angus Smith Drive, Douglas QLD 4814, Australia. Email: usman.malabu@jcu.edu.au. 


\section{Materials and methods}

Study design and setting

This study was a retrospective review of self-presented patients with symptoms of and confirmed to have diabetes mellitus (DM) requiring hospital admission at the Kimbe General Hospital (KGH), PNG, from January 2009 to December 2012. KGH is the largest hospital in West New Britain Province treating patients across the region. Approval was obtained from the hospital's research ethics committee and informed consent was sought from the participants.

\section{Study population}

The study population included all subjects admitted with newly diagnosed DM on presentation to the hospital's adult medical wards during the study period. All subjects admitted to the wards were manually recorded in a proforma. Diabetes was diagnosed according to the American Diabetes Association National Diabetes Data Group and WHO criteria for DM. ${ }^{10,11}$ All subjects had random blood glucose of $>11.1 \mathrm{mmol} / \mathrm{L}$ along with symptoms leading to their presentation to the hospital's emergency department. All patients responded to diet and oral hypoglycemic agents either glibenclamide or metformin alone or both. None of the patients went home on insulin. There were no biochemical features of diabetic ketoacidosis. In particular there were no significant urinary ketones or metabolic acidosis at the time of presentation. None of the subjects had hyperosmolar hyperglycemic crises. Patients were excluded from the study if they were previously diagnosed to have diabetes or newly diagnosed DM patients who were managed as outpatient or had no symptoms at the time of the diagnosis to warrant hospital admission for management of the condition.

Data collection and analysis

Data of the newly diagnosed DM patients were sourced from the medical record register. Variables collected included year of admission, age, gender, province of origin and place of residence represented as Kimbe urban or rural areas. Kimbe urban was defined as Kimbe town and surrounding suburb. The latter comprises mainly immigrants from other provinces, mining workers and their families. Data were double-entered into EpiData, version 3.1 (EpiData Association, Odense, Denmark) and validated. The final data set was then analyzed after correcting for discordance. The chi-square test was performed to test for association between two categorical factors, and the unpaired ttest was used to assess the relationship between continuous and dichotomous categorical factors. For continuous data that were not normally distributed, the results of t-test were confirmed using the Mann -Whitney test. Results were considered statistically significant at a $\mathrm{p}$ value less than 0.05 . These analyses were performed using SPSS version 11.0 (Chicago, IL, USA).

\section{Results}

Over a period of 4 years, 144 subjects were reviewed on admission to have DM at our hospital medical wards. Nineteen subjects were excluded from the study due to incomplete records. The remaining 125 patients comprising 70 males and 55 females were confirmed to have diabetes in this study with a ratio of 1.1: 1 .

Majority of the patients were of young population aged $<50$ years representing $72 \%$ of the cohort as shown in Figure 1. Population of Kimbe town progressively increased over the years with rapid rise between 2000 and 2010 as shown in Figure 2 and is thought to rapidly upswing further in recent years. On the other hand, there was an upsurge of newly diagnosed diabetes at KGH predominantly amongst residents of Kimbe town and its suburb and less for residents in rural areas as shown in Figure 3.

Greater number of subjects who identified their province of origin as coastal were diagnosed with DM compared to lesser numbers for subjects of non-coastal

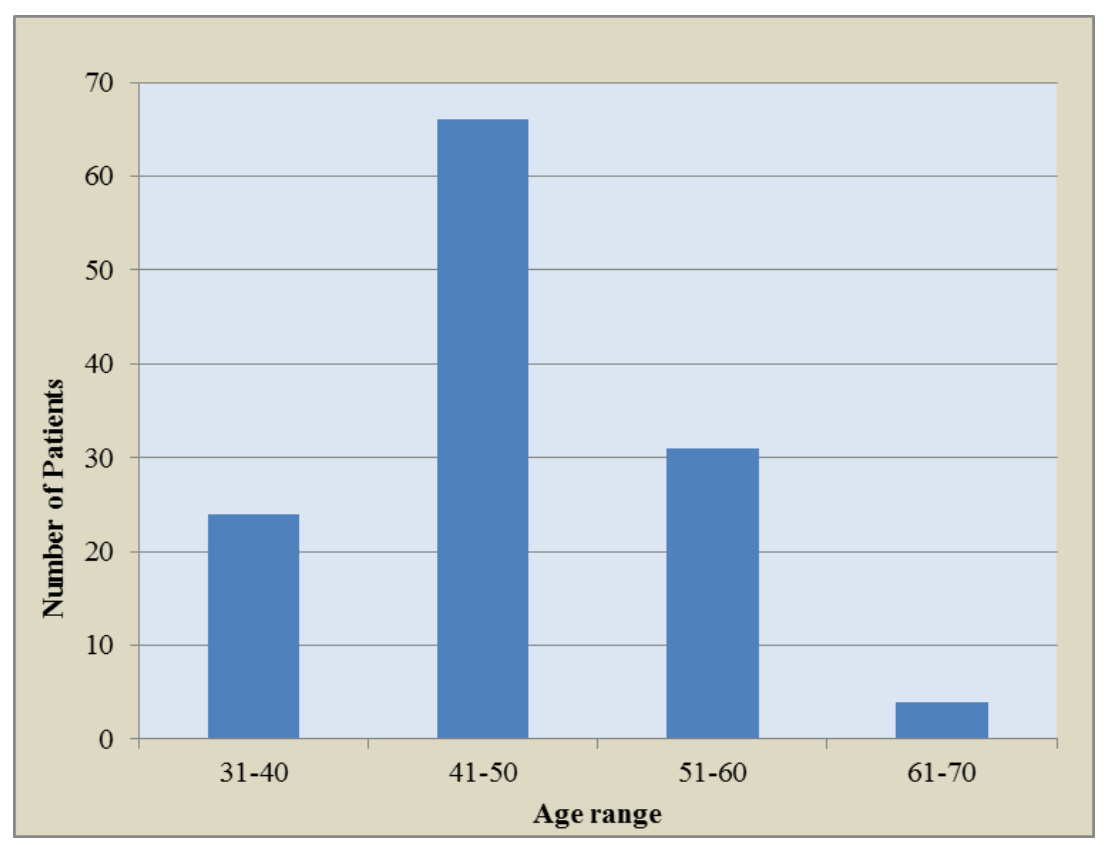

Figure 1: Patients admitted with Newly Diagnosed Diabetes at Kimbe General Hospital, 2009 to 2012 aged $31-70$ years 


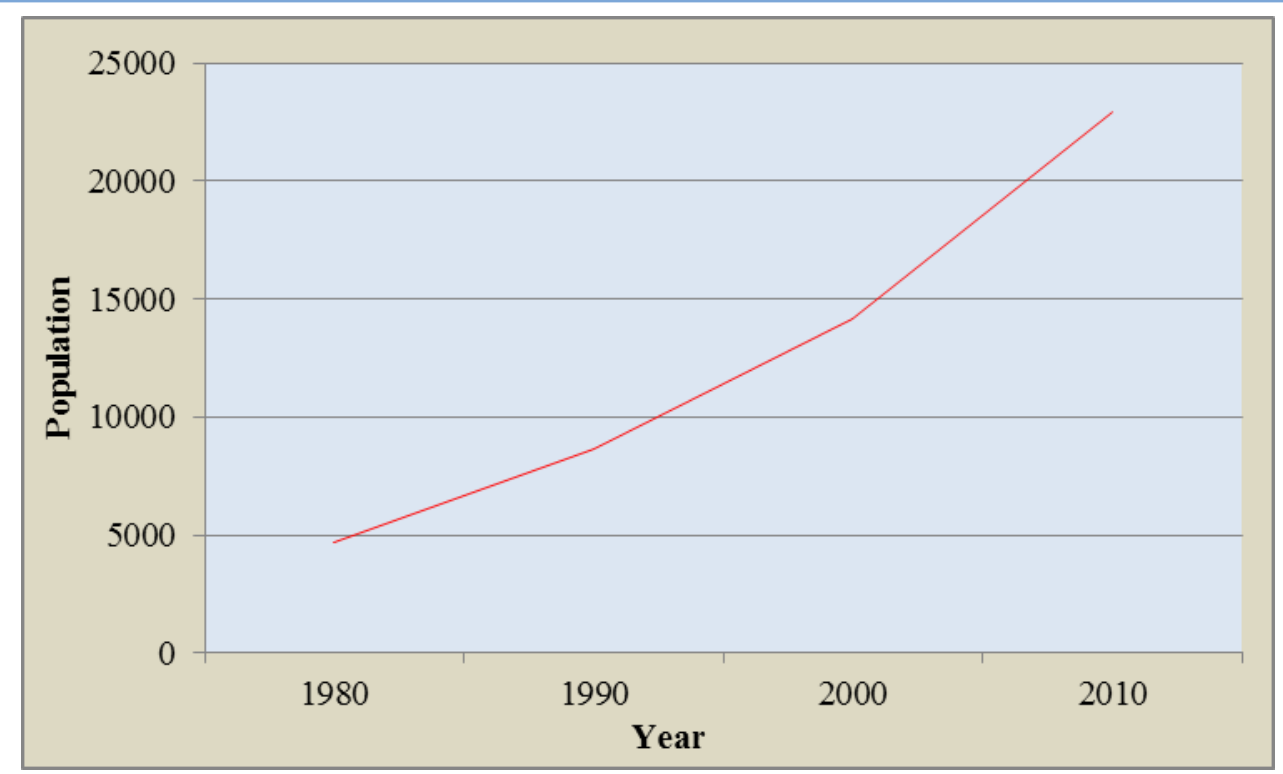

Figure 2: Population of Kimbe town (excluding its suburb) over 30 years from 1980 to 2010 showing rapid rise from year 2000

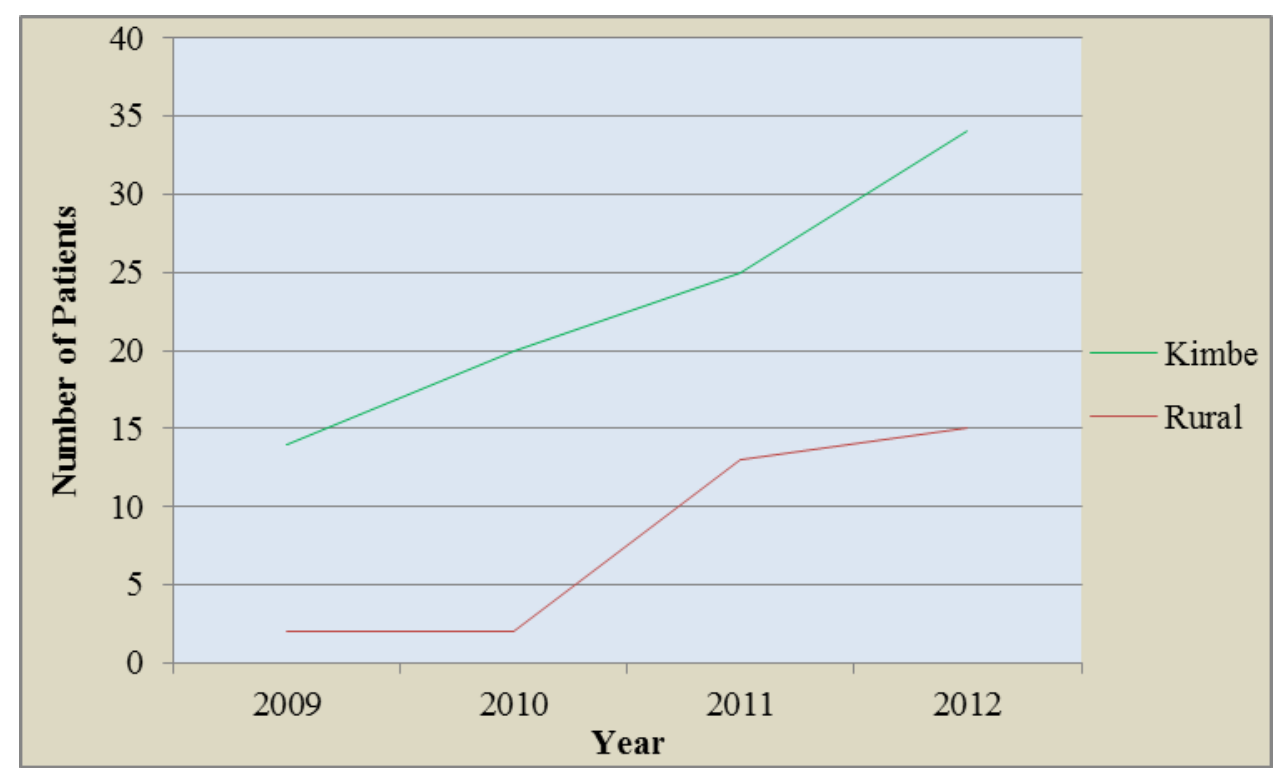

Figure 3: Patients admitted with newly diagnosed diabetes at Kimbe General Hospital from 2009 to 2012 based on area of residence

province of origin, $\mathrm{p}<0.05$. Distribution of province of origin revealed 111 subjects for Coastal comprising of West New Britain 52, East New Britain 37, National Capital District 9, Central Province 6, North Solomons 4, and Milne Bay 3.On the other hand 8 and 6 newly diagnosed DM patients were of Mainland (East Sepik) and Highlands respectively.

\section{Discussion}

We have reported high rate of diabetes in a rapidly urbanised population compared to rural areas in a low/ middle income Asia-Pacific country. Of the number of DM diagnosed at the regional hospital $74.4 \%$ reside in or around the provincial capital. Kimbe town has witnessed an exponential rise of population by $500 \%$ in 30 years and is likely to quadruple the current figure by 2020 in view of increased industrial and mining activities which are linked to rural-urban migration. ${ }^{9,12,13}$ The significance of this finding suggests rapid expansion of the population may have impact on in- creasing the risk of diabetes likely related to lifestyle changes related to modernisation. Findings of many studies have shown clearly a positive rural-urban gradient in prevalence of diabetes. ${ }^{14,15}$ Our findings support similar report of $30 \%$ higher prevalence of diabetes in PNG's capital city compared to $1 \%$ in rural areas. ${ }^{16}$ Similar observations were reported in other Pacific, African and Caribbean countries. ${ }^{13,17-18}$ In contrast, Lin et al. ${ }^{19}$ reported high prevalence of diabetes in both rural and urban areas in Pacific Tongans. This suggests adoption of new lifestyle which is closely associated with urbanisation in certain countries might not be applicable to some indigenous populations who are at high risk of diabetes irrespective of the rural-urban status. Our finding is novel in that this is the first documentation of high rate of diabetes in this area where more attention is directed to communicable diseases and less emphasis on non-infectious ailments. With the high prevalence of communicable diseases including 
HIV/AIDS, malaria and tuberculosis in the region, this represents a double burden on the over-stretched and fund -scarce healthcare. ${ }^{20}$ It calls for urgent need for future planning in the form of health education on prevention of diabetes and other non-communicable diseases. Our finding suggests a tip of the iceberg on extent and burden of diabetes in the area. It is important to note that all our patients were not known to have diabetes prior to the hospital visit yet they presented with florid symptoms warranting their admissions for stabilisation of blood glucose levels. This means a substantial number of asymptomatic undiagnosed diabetic subjects were living in the region due to lack of awareness among the populace. This is in support of population reports from other Asia-Pacific countries which showed more than four unknown cases of diabetes exist for each known case. $^{21}$

Earlier reports in PNG reported DM to be more common among pockets of coastal people of Austronesian admixture. ${ }^{22}$ Furthermore, with the urbanisation, diabetes is increasing alarmingly in the same group of populations in the country. ${ }^{23}$ As minority of our study population's province of origin was of non-mainland and highlanders, most of the cases of DM were of coastal descent. The reason for the notable higher risk of DM amongst the coastal peoples is not clear although adoption of western life style was suggested as a possible cause. ${ }^{6,15}$ More prospective studies are needed to further characterise the finding.

Interestingly, most of the diagnosed DM population in our study was young males within productive age of $<50$ years as noted by others. ${ }^{24}$ This shows the need to prevent $\mathrm{DM}$ in the first instance as once complications ensure, treatment is either unaffordable or unavailable to the average local population or both. ${ }^{25,26}$ For instance Savige et $a .^{27}$ reported $65 \%$ mortality from diabetes complications amongst subjects diagnosed with DM in PNG over a follow up period of 14 years. At our hospital, current situation showed no diabetes educator or diabetes specialist to follow up the diagnosed DM patients for prevention of complications. The importance of prevention and maintenance of the optimal glycaemic control could not be over emphasised. To this end community-based surveillance and prevention programs for diabetes and other non-communicable diseases have been established in some Asia-Pacific countries with promising results. ${ }^{28}$

Our report faced potential limitations including nonavailability of up-to-date population data on Kimbe Suburb and Kimbe Town beyond 2010 which we believe have surged in recent years and the trend is rising at exponential rate. ${ }^{8}$ Furthermore, our reliance on the health professional's accuracy of information documented in patients' medical records at the time of admission in diagnosing DM may potentially pose a significant limitation to this study particularly regarding availability and reliability of the data. In order to overcome this limitation, we accessed data from various sections of patients' medical charts including patients' clinical record in the pathology and emergency departments and corroborate with data obtained from the medical ward record. Only one member from the research team performed the data collection in order to maintain standard and continuity of methods of data extraction. We were also faced with lack of documentation of anthropometric measurements and other biochemical profile required for further characterisation of the DM syndrome. Furthermore, the biochemical profile leading to the diagnosis of diabetes was limited to at the time of admission and did not address details on management and clinical course during the hospital admission. An interesting finding of our study is the rapid increase in number of newly diagnosed diabetes within a short period of time. Indeed compared to 2009, 2012 showed 3fold increase in the hospital admission for newly diagnosed diabetes in the province contributed largely by the urban population. Breakdown of the diabetic population also showed similar pattern of progressive increase in DM within the same period of time. Although increased awareness amongst the healthcare providers might be responsible for the upward trend of the disease, we believe the changes are real in that basic laboratory tests including blood glucose levels were routinely performed at the hospital throughout the period of the study. Lastly, it is important to note that there is a limitation to retrospective studies in general. Observations derived from such studies may contain some missing information and thus may serve as a stimulus to further prospective work to clarify findings. The present work must be interpreted in the knowledge of the defects inherent in such studies. Despite these, our result is consistent with other reports. ${ }^{14,15}$

\section{Conclusion}

This is the first study on pattern of diabetes in a rapidly urbanised population of West New Britain Province of Asia-Pacific PNG showing high rate of diabetes in coastal-urban settlements compared to subjects who live in traditional rural areas. It highlights the need for strategic health care planning for the high risk diabetic population through increased screening, public awareness and over all prevention of the disease in the area. More studies are needed to further characterise our findings.

\section{Acknowledgements}

The authors would like to thank Professor John Vince, School of Medicine and Health Sciences, University of Papua New Guinea for guidance and professional advice, and Ms Esther Apamumu and Mr Charles Mone for assisting in data collection and statistical advice respectively.

\section{Competing interest}

The authors declared no potential conflicts of interest with respect to the research, authorship, and/or publication of this article.

\section{References}

1. World Health Day 2016: Beat diabetes. http://www.who.int/campaigns/world-healthday/2016/en/(accessed Nov 2016)

2. World Health Organization. Chronic diseases and health promotion. http:// www.who.int/chp/chronic_disease_report/ en/ (accessed Nov 2016)

3. Nanditha A, Ma RC, Ramachandran A, Snehalatha C, Chan JC, Chia KS, et al. 
Diabetes in Asia and the Pacific: Implications for the Global Epidemic. Diabetes Care 2016;39 (3):472-85.

4. Rooney PJ. Papua New Guinea - Health. The Diabetes, Attitudes, Wishes and Needs (DAWN) Study. http:// papuanewguineahealth.com/2013/01/20/themanagement-of-diabetes-and-other-lifestylediseases-in-papua-new-guinea/ (accessed Nov 2016)

5. Goddard CL. The Sugarman Project: Fighting Diabetes in Bougainville: 2010 report. Victoria, Australia: Rotary Club of Brighton, 2010.

6. Taufa T, Benjamin AL. Diabetes: the by-product of westernization in Papua New Guinea. $P N G$ Med J 2001;44(3-4):108-10.

7. Lesley J, Manning LA, Ogle GD. A survey of diabetes services in hospitals in Papua New Guinea. P N G Med J 2001;44(3-4):88-95.

8. PNG PORTS Corporation Limited. Kimbe Port. http://www.pngports.com.pg/index.php/kimbeport (accessed Nov 2016)

9. Papua New Guinea. Independent State of Papua New Guinea. Provinces. http:// www.citypopulation.de/PapuaNewGuinea.html (accessed Nov 2016)

10. American Diabetes Association Diagnosis and classification of diabetes mellitus. Diabetes Care 2014;37(Suppl. 1):S81-S90.

11. World Health Organization. Definition and diagnosis of diabetes mellitus and intermediate hyperglycaemia: Report of a WHO/IDF Consultation. Geneva: WHO, 2006.

12. Spickett J, Batmunkh T, Jones S. Health impact assessment in Mongolia: current situation, directions, and challenges. Asia Pac J Public Health 2015;27(2):NP2732-9.

13. Oyebode O, Pape UJ, Laverty AA, Lee JT, Bhan $\mathrm{N}$, Millett C. Rural, urban and migrant differences in non-communicable disease riskfactors in middle income countries: a crosssectional study of WHO-SAGE data. PLoS One 2015;10(4):e0122747.

14. Mbanya JC, Assah FK, Saji J, Atanga EN. Obesity and type 2 diabetes in Sub-Sahara Africa. Curr Diab Rep 2014;14(7):501.

15. Kapur A, Schmidt MI, Barceló A. Diabetes in Socioeconomically Vulnerable Populations. Int $J$ Endocrinol 2015;2015:247636.

16. Martin FI, Wyatt GB, Griew AR, Haurahelia M, Higginbotham L. Diabetes mellitus in urban and rural communities in Papua New Guinea. Studies of prevalence and plasma insulin. Diabetologia 1980;18(5):369-74.
17. Bagley A, Malabu UH. Diabetes epidemic in the Asia Pacific region: has hemoglobin A1C finally earned its place as a diagnostic tool? Asian Pac $J$ Trop Biomed 2014;4(2):85-9.

18. Kessaram T, McKenzie J, Girin N, et al. Noncommunicable diseases and risk factors in adult populations of several Pacific Islands: results from the WHO STEP-wise approach to surveillance. A ust N Z J Public Health 2015;39 (4):336-43.

19. Lin S, Hufanga S, Linhart C, et al. Diabetes and Obesity Trends in Tonga Over 40 Years. Asia Pac J Public Health 2016. pii: 1010539516645156.

20. Tin ST, Iro G, Gadabu E, Colagiuri R. Counting the Cost of Diabetes in the Solomon Islands and Nauru. PLoS One 2015;10(12):e0145603.

21. King H, Finch C, Koki G, King LF, Alpers M, Zimmet P. Glucose tolerance in Papua New Guinea: comparison of Austronesian and nonAustronesian communities of Karkar Island. Diabet Med 1991;8(5):481-8.

22. Viney $\mathrm{K}$, Brostrom $\mathrm{R}$, Nasa J, Defang $\mathrm{R}$, Kienene T. Diabetes and tuberculosis in the Pacific Islands region. Lancet Diabetes Endocrinol 2014;2(12):932.

23. Dowse GK, Spark RA, Mavo B, Hodge AM, Erasmus RT, Gwalimu M, et al. Extraordinary prevalence of non-insulin-dependent diabetes mellitus and bimodal plasma glucose distribution in the Wanigela people of Papua New Guinea. Med J Aust 1994;160(12):767-74.

24. Brian G, Ramke J, Maher L, Page A, Szetu J. The prevalence of diabetes among adults aged 40 years and over in Fiji. N Z Med $J$ 2010;123 (1327):68-75.

25. Cho NH. Diabetes burden and prevention in Korea and the Western Pacific Region. Diabetes Res Clin Pract 2014;106 Suppl 2:S282-7.

26. Low WY, Lee YK, Samy AL. Noncommunicable diseases in the Asia-Pacific region: Prevalence, risk factors and communitybased prevention. Int J Occup Med Environ Health 2015;28(1):20-6.

27. Savige J, Martin FI. Mortality and morbidity of diabetes in Papua New Guinea. Diabetologia 1982;23(2):136-7.

28. Low WY, Lee YK, Samy AL. Noncommunicable diseases in the Asia-Pacific region: Prevalence, risk factors and communitybased prevention. Int J Occup Med Environ Health 2015;28(1):20-6. 